\title{
Controlled atmospheres against insect pests in museums: a review and some considerations
}

\begin{abstract}
Controlled atmospheres using nitrogen represent a safe and effective method for both objects and human health. The use of this technique against pests in museums has received an increasing amount of interest during the last twenty years. This paper looks at the researches into anoxic treatments that use nitrogen from the late ' 80 s until now.

At the moment, the recommended protocol suggests an oxygen percentage below $1 \%$ for at least three weeks. Considering that the major practical problems of controlled atmospheres are connected to treatment time and low oxygen percentage, it is very important to develop more flexible protocols that consider higher oxygen percentages or shorter treatment times, exploiting temperature and/or relative humidity. At oxygen percentage higher than those commonly used, temperature and relative humidity are very critical to insects' development and success. Preliminary data (unpublished) show that it is possible to adapt the application of the controlled atmospheres to different situations, taking advantage of favorable conditions already present in the considered situation and at the same time to use the other parameters at more favorable levels.
\end{abstract}

Key words: cultural heritage, relative humidity, protocol.

\section{INTRODUCTION}

Control of insect pests in conservation institutions was based on pesticide applications at least until the eighties. Of course the high use of chemicals has led to accumulations of residues in the environment (Glastrup, 1987; Koestler et al., 1993). Reviews concerning problems caused by biocides used on cultural objects can be found in Allsopp \& Seal (1985), Story (1985), Dawson (1988), Caneva et al. (1991), and Pinniger (1994). Biocides are reactive products and many, if not all, can cause alterations in some kinds of works of art.

An array of preventive and "non chemical" control methods should represent the rule to be adopted to solve pest problems (Strang, 1998). Controlled atmospheres using nitrogen represent a safe and effective method for both objects and human health. Nitrogen is nontoxic, non-flammable, and non-reactive. This technique, in fact, is particularly useful for very vulnerable objects, which might be damaged by low or high 
temperature treatments (Pinniger, 2010). After 150 days of treatment, painting materials showed no visual effects as a consequence of exposure to nitrogen (Koestler et al., 1993; Koestler et al., 2004). Despite the fact that an inert atmosphere "retards color fading" of most organic colorants (Arney et al., 1979; Burke, 1992), a possible negative effect, due to oxygen deprivation, is a change in specific pigments (e.g. Prussian blue) (Rowe, 2004).

Use of controlled atmospheres against pests in museums has received an increasing amount of interest during the last twenty years (Gilberg, 1989; Valentin, 1990; Gilberg, 1991; Daniel et al., 1993; Hanlon et al., 1993; Reichmuth et al., 1993; Valentin, 1993; Kaplan \& Schulte, 1996; Newton et al., 1996; Reirson et al., 1996; Rust et al., 1996; Grassi, 1997; Nielse, 1998; Selwitz and Maekawa, 1998; Kigawa et al., 2001; Valentin et al., 2002; Bergh et al., 2003; Brandon \& Hanlon, 2003; Child, 2007; Child \& Pinniger, 2008). This research especially addressed two aspects of the method: the oxygen percentage (but always very low, between $0.03 \%$ and $1.0 \%$ ) (Child \& Pinniger, 2008) and the treatment time, which varied from a few days to weeks (Gilberg, 1991; Grassi, 1997; Daniel et al., 1993; Hanlon et al., 1993; Pinniger \& Child, 1996; Valentin et al., 2002; Bergh et al., 2003).

At the moment, the recommended protocol, which Gilberg (1991) validated for Tineola bisselliella (Hummel), Lasioderma serricorne (Fabricius), Stegobium paniceum (Linnaeus), Anthrenus vorax (Linnaeus), recommends an oxygen percentage below $1 \%$ for at least three weeks.

According to professionals, the most common problems are: 1) long treatment times that, together with low oxygen percentages, cause high costs and difficulties to the management of conservation institutions (Selwitz \& Maekawa, 1998), 2) difficulty in achieving and maintaining such low oxygen concentrations; if the oxygen level increases during the treatment, it has to be repeated.

Regarding the first point, the total time required for treatment is the sum of the time necessary for the controlled atmosphere to permeate the substrate plus the time needed to obtain total mortality of the insects. Therefore, the exposure time is affected by the oxygen drop time, not only in the "bubble" where the treatment is done, but especially within the object in which the insect lives. The oxygen desorption time of objects depends intrinsically on the nature of the materials, on the thickness of the objects to be treated (normally, wood needs more time for a uniform distribution than textiles) (Reichmuth, 1993), on their volume and on the anoxia chamber volume. In addition, it varies as a function of the permeability of the materials to the gas mixture that replaces oxygen in the material. Gunn et al. (2006) elaborated a modelling of nitrogen diffusion in porous objects that makes it possible to predict oxygen desorption time, in relation to the nature of the material and the size of the objects, and therefore to estimate achievement of anoxia at the core of a treated object. They concluded that the length of treatment depends closely on the desorption time and that the oxygen drop time is between 1 and 2 days for most objects. It is therefore advisable that this aspect is studied by both an entomologist and a physicist.

With regard to the second point (use of very low oxygen concentrations), some considerations are necessary on the way oxygen deprivation acts on insects. The effects 
of different oxygen percentages in the controlled atmosphere on insect metabolism are different. At oxygen concentrations below 3\%, in order to meet their energy requirements, insects adopt an anaerobic metabolism (Edwards, 1953; Wegener, 1993; Mitcham et al., 2006). With oxygen levels ranging from $3 \%$ to $5 \%$, insects face the reduced availability of oxygen by reducing the oxidative metabolism. Neither strategy produces enough energy to maintain a standard metabolic level, obliging the insects to reduce this and, as a consequence, their energy demand (Hochachka et al., 1993; Mitcham et $a l ., 2006)$. An accumulation of toxic end products, together with a very slow metabolism, is the cause of stress that results in death (Ofuya \& Reichmuth, 2002).

At oxygen concentrations above $5 \%$, the insects increase their respiratory rate in order to take in the same amount of oxygen. The increase in respiratory rate results in dehydration due to prolonged opening of the stigma, especially at high temperatures and low humidity (Emekci et al., 2002; Mitcham et al., 2006). Jay et al. (1971) studied the relationship between mortality and R.H., by examining the death rate of red flour beetles Tribolium castaneum (Herbst) and confused flour beetles Tribolium confusum Jacquelin du Val in a nitrogen atmosphere, containing between $0.8 \%$ and $1 \%$ oxygen, after 24 hours at R.H. of 9\%, 33\%, 54\%, and 68\%. Both species showed a marked increase in mortality as the R.H. decreased, but they died also at high R.H. (68\%). Considering the possibility of using controlled atmospheres with higher oxygen percentages, anoxia treatments were shown to be effective at oxygen percentages from 3 to $10 \%$, in at most one week, at temperatures between $20^{\circ} \mathrm{C}$ and $40^{\circ} \mathrm{C}$ (Chiappini et al., 2009), taking advantage of the "positive influence of a temperature increase in order to compensate for the effects of the reduced anoxia".

In this case, the efficacy of treatments with oxygen concentrations higher than $5 \%$ was certainly due also to the low R.H. registered in the experiments, always lower than 15\% (Chiappini et al., 2009).

Humidity influences the survival of insects and dry conditions generally appear to be highly unfavourable to most insects (Child, 2007). Controlled atmospheres increase the action of low humidity, by prolonging opening of the spiracles, thereby permitting rapid loss of water. In the same way, high humidity suppresses the desiccation mechanism (Gullan \& Cranston, 1994; Emekci et al., 2002; Mitcham et al., 2006).

\section{DISCUSSION AND CONCLUSIONS}

Considering that the major practical problems of controlled atmospheres are connected to treatment time and low oxygen percentage, and that these parameters are strictly related to each other and to those of the microclimate (temperature and relative humidity), it is very important to develop more flexible protocols that consider higher oxygen percentages or shorter treatment times, exploiting temperature and/or relative humidity.

The availability of these data also allows us to adapt to different situations, even to take advantage of favourable conditions already present and to use the other parameters at more favourable levels. 
Temperature and relative humidity are critical to insects' developmental success. Considering the positive correlation between metabolic rate and temperature in insects (Calderwood, 1961), anoxic treatment is, of course, temperature-dependent to a high degree. It is generally agreed to be relatively ineffective at temperatures below $15^{\circ} \mathrm{C}$ (Child, 2007). The effect of high temperatures can be useful for speeding up the treatment time (Navarro \& Calderon, 1980; Chapman, 1998).

Valentin (1993) studied the possibility of shortening treatment time, rising the temperature, at a very low oxygen percentage $(0.03 \%)$. Complete eradication of Anobium punctatum (DeGeer) was achieved after 5 days at $30^{\circ} \mathrm{C}(50 \%$ R.H. $)$, L. serricorne, required 8 days at $25^{\circ} \mathrm{C}$ ( $50 \%$ R.H.), or 9 days at $20^{\circ} \mathrm{C}$ ( $40 \%$ R.H.), while for Hylotrupes bajulus an exposure time of 10 days at $30^{\circ} \mathrm{C}\left(40 \%\right.$ R.H.) or 20 days at $20^{\circ} \mathrm{C}$ was necessary (Valentin, 1993), thus demonstrating the efficacy of exposure times much shorter than the standard of 21 days.

In some cases, at low oxygen percentages, a total mortality was reported even at not very high temperatures. It was reached in less than 4 days at $25.5^{\circ} \mathrm{C}(55 \% \mathrm{R} . \mathrm{H}$., $<0.1 \%$ oxygen percentage) for adults, larvae, and eggs of Tineidae (Rust et al., 1996) and in only 3 days at $25^{\circ} \mathrm{C}(55 \%$ R.H., $0.3 \%$ oxygen percentage $)$ for six Dermestidae species (Bergh et al., 2003).

If higher oxygen percentages are taken into account, at which, as we have already clarified, water loss becomes a key factor for mortality, relative humidity should also be considered.

Some preliminary results on adults of the food pest, T. confusum, are extremely promising. At $3 \pm 0.1 \%$ oxygen, total mortality was obtained in 5 days of treatment at $32 \pm 1{ }^{\circ} \mathrm{C}$ and $30 \pm 2 \%$ R.H., while lower mortality (86\%) was registered at the same treatment time ( 5 days), oxygen percentage $(3 \pm 0.1 \%)$ and temperature $\left(32 \pm 1{ }^{\circ} \mathrm{C}\right)$ but at higher relative humidity $(50 \pm 2 \%$ R.H. $)$. A similar result was obtained also at a higher oxygen percentage; at $5 \pm 0.1 \%$ oxygen total mortality was obtained in 4 days of treatment at $35 \pm 1{ }^{\circ} \mathrm{C}$ and $30 \pm 2 \%$ R.H.. These data demonstrate the high correlation existing between temperature and relative humidity for controlled atmosphere efficacy (unpublished data), especially at higher oxygen percentages.

In many conservation institutions all over the world, recommended temperature and relative humidity conditions $\left(25^{\circ} \mathrm{C}, 45-50 \%\right.$ R.H. $)$ are not sustainable; moreover, many times a wide range of relative humidity could be suitable; for paper conservation a R.H. from 35\% to 50\% is acceptable, as pointed out by Dean (www.nyalgro.org/ enemies $\% 20$ of $\% 20$ paper05.ppt). However, low humidity is preferable to high. Miller in 1993 (http://www.artframe.us/Article-EnemiesofPaper.pdf), talking about the conservation of paper, underlines that $50 \%$ is the ideal value, but the most important factor is not 50\% R.H., but that it remains constant. Humidity changes are in fact the main cause of paper materials damage.

From his experience Michalski (1993) identifies real examples of incorrect relative humidity in museums, falling into one of four categories: "damp, above or below a critical humidity, any humidity over $0 \%$, and humidity fluctuations".

Also in particular situations, such as moving or building restoration, the "correct" 
temperature or humidity could be temporarily lost. In addition some institutions (e.g. Canadian libraries and archives) opt to achieve mass desiccation for free during the winter by using heating systems with no humidifiers (Michalski, 1993).

Therefore, why not considering the opportunity of treatment under more favourable conditions?

With respect to relative humidity and oxygen percentage also the technique chosen could acquire importance. A static approach can be optimal when the previous R.H. is low and therefore useful for enhancement of treatment efficacy while a dynamic approach, which requires humidification to avoid hygrometric shock to museum objects during treatment (Child \& Pinniger, 2008), could be used when the R.H. is relatively high and does not have to be lowered.

Some additional considerations are necessary. Considering that survival parameters for many insect pest species have been studied and are well understood and that for holometabolous insects the ability to live in hypoxia is stage-specific (Hoback \& Stanley, 2001), a systematic study is necessary in which the museum insect mortality, of various species is determined following exposure to a range of oxygen concentrations for varying periods of time at different temperatures and relative humidity.

Furthermore, most of the tests on the mortality of the insects in cultural property in an anoxic environment have been done not on laboratory reared insects, but on "natural populations" in objects to be treated, not knowing their precise age or even their health. Therefore, in literature it is often not basic research on the insects that is presented, but treatments to test the functionality of a specific instrument (Gilberg, 1990; Brandon \& Hanlon, 2003; Valentin, 2002).

Information in literature on respiration rates of the various developmental stages of insects is very rare. Gilberg (1991), Hoback \& Stanley (2001), and Child (2007), underline that it appears that investigation into insect adaptations to hypoxic and anoxic environments is an emerging field of inquiry, but these challenges are still evident today.

\section{REFERENCES}

Alsopp D., Seal K. J., 1986 - Introduction to Biodeterioration - Edward Arnold Ltd, 41 Bedford Square, London WC1B 3DQ, 136 pp.

Arney J.S., Jacobs A.J., Newman R., 1979 - Influence of oxygen on the fading of organic colorants. Journal of American Institute for Conservation, 18: 108-117.

Bergh J.E., Stengard H.L., Vagn Jensen K.M., Nielsen P.V., 2003 - The effect of anoxic treatment on the larvae of six species of dermestids (Coleoptera). Journal of Applied Entomology, 127: 317-321.

Brandon J., Hanlon G., 2003 - A low tech method for insect eradication using Ageless TM. WAG Postprints, Arlington, Virginia.

Burke J., 1992 - Vapor barrier films. WAAC (Western Association of Art Conservation) Newsletter, 14 (2):13-17.

CAlderwood W.A., 1961 - Demethabolic rate of the flour beetle, Tribolium confusum. Transactions of the Kansas Academy of Science, 64: 150-152. 
Caneva G., Nugari M.P., Salvadori O., 1991 - Biology in the Conservation of Works of Art. ICCROM, Rome, $182 \mathrm{pp}$.

Chapman R.F., 1998 - The Insects: structure and function, 4th ed. Harvard University Press, Cambridge, MA.

Chiappini E., Molinari P., Cravedi P., 2009 - Mortality of Tribolium confusum J. du Val (Coleoptera: Tenebrionidae) in controlled atmospheres at different oxygen percentages. Journal of Stored Products Research, 45: 10-13.

CHILD R.E., 2007 - Insect damage as a function of climate. Museum Microclimates, National Museum of Denmark, 57-60.

Child R.E., Pinniger D., 2008 - Using anoxia to kill insect pests: methodologies and methods. In: ICOM Committee for Conservation, Fifteenth Triennial Conference, New Delhi, 563567.

Daniel V., Hanlon G., Maekawa S., 1993 - Eradication of insect pests in museums using nitrogen. Waac Newsletter, 15 (3): 15-19.

DAwson J., 1988 - The effects of insecticides on museum artifacts and materials. In: A Guide to Museum Pest Control, Whasington DC, USA, 135-150.

Donahaye E.J., NAvarro S., 2000 - Comparisons of energy reserves among strains of Tribolium castaneum selected for resistance to hipoxia and hypercarbia, and the unselected strain. Journal of Stored Products Research, 36: 223-234.

Edwards G.A., 1953 - Respiratory metabolism. - In: Roeder K.D., Insect Physiology. New York, Chapman \& Hall Limited, London: 96-146.

Emekci M., Navarro S., Donahaye E., Rindner M., Azrieli A., 2002 - Respiration of Tribolium castaneum (Herbst) at reduced oxygen concentrations. Journal of Stored Products Research, 38: 413-425.

GilBeRG M., 1989 - Inert atmosphere fumigation of museum objects. Studies in Conservation, 34: $80-84$.

GILBERG M., 1990 - Inert atmosphere disinfestation using AGELESS oxygen scavenger. In: ICOM Committee for Conservation Ninth Triennial Meeting, Dresden, 812-816.

Gilberg M., 1991 - The effects of low oxygen atmospheres on museum pests. Studies in Conservation, 36: 93-98.

Glastrup J., 1987 - Insecticide analysis by gas chromatography in the stores of the Danish National Museum's ethnographic collection. Studies in Conservation, 32: 59-64.

Grassi, R., 2010 - Disinfestazione dei locali e dei codici miniati e libri pergamenacei del museo aggrediti da insetti anobidi (tarli). Forum Iulii, Annuario del museo nazionale di Cividale del Friuli.

Gullan P.J., Cranston P.S., 1994 - The insects: an outline of entomology. Chapman \& Hall, London, $469 \mathrm{pp}$.

Gunn M., Ziaeepour H., Merizzi F., Naffah C., 2006 - Anoxia, Treatment by oxygen deprivation: optimizing treatment time of museum objects. http://arxiv.org/ftp/physics/papers/0611/0611199.pdf

Hoвack W.W., Stanley D.W., 2001 - Insects in hypoxia. Journal of Insect Physiology, 47: 533542.

Hochachka P.W., Nener J.C., Hoar J., Saurez R.K., Hand S.C., 1993 - Disconnecting metabolism from adenylate control during extreme oxygen limitation. Canadian Journal of Zoology, 71: 1267-1270.

Jay E.G., Arbogast R.T., Pearman G.C., 1971 - Relative humidity: its importance in the control of stored product insects with modified atmospheric gas concentrations. Journal of Stored Products Research, 6: 325-329. 
Kaplan H.A., Schulte L.K., 1996 - Oxygen deprivation for the extermination of insects infesting architectural drawings. The Paper Conservator, 20: 22-26.

Koestler R.J., Parreira E., Santoro E.D., Noble P., 1993 - Visual effects of selected biocides on easel painting materials. Studies in Conservation, 38: 265-273.

Koestler R.J., Tavzes Č., Pohleven F., 2004 - A new approach on conservation of wooden heritage. In: Proceedings of the 35th Annual Meeting Ljubljana, Slovenia 6-10 June 2004.

MichaLSKi S., 1993 - Relative humidity: A discussion of correct/incorrect values. In: ICOM Committee for Conservation $10^{\text {th }}$ Triennal Meeting, Washington D.C., USA, 22-27 August.

Mitcham E., Martin T., Zhou S., 2006 - The mode of action of insecticidal controlled atmospheres. Bulletin of Entomological Research, 96: 213-222.

Navarro S., CALderon M., 1980 - Integrated approach to the use of controlled atmospheres for insect control in grain storage. Controlled Atmosphere Storage of Grains, Elsevier 73-78.

Nayar K.K., Ananthakrishnan T.N., David B.V., 1976 - General and Applied Entomology. Tata MC Graw-Hill, New Delhi, 889 pp.

Newton J., Abey-Koch A., Pinniger D., 1996 - Controlled atmosphere treatment of textile pests in antique curtains using nitrogen hypoxia, a case study. In: Proceedings of the $2^{\text {nd }}$ Conference on Insect Pests in the Urban Environment, Edinburgh, UK, 329-339.

NiELSEN P.B., 1998 - State of art incubator for controlled atmosphere studies. In: Proceedings of the $3^{\text {rd }}$ Nordic Symposium on Insect Pest Control in Museums, 24-25 September 1998, Stockholm, Sweden, 80-84.

Ofuya T.I., Reichmuth C., 2002 - Effect of relative humidity on the susceptibility of Callosobruchus maculatus (Fabricius) (Coleoptera: Bruchidae) to two modified atmospheres. Journal of Stored Products Research, 38: 139-146.

Pinniger D. B., Child R. E., 1996 - Insecticides: optimising their performance and targeting their use in museums. Proceedings of 3rd International Conference on Biodeterioration of Cultural Property, Bangkok, Thailand 1995.

Pinniger D., 1994 - Insect Pests in Museums. $3^{\text {rd }}$ Edition - Archetype Publications Ltd. 31-34, Gordon Square, London WC1H 0PY, 58 pp.

Pinniger D., 2010 - Saving our heritage - pest management in museums and historic housesResearch Information Ltd, 239-241. http://www.pestoutlook.com

Reichmuth C., Unger A., Unger W., Blasum G., Piening H., Rohede-Hehr P., Plarre R., PöschKo M., WudtKe A., 1993 - Nitrogen-flow fumigation for the preservation of wood textiles, and other organic materia from insect damage. In: Proceedings of International Conference on Controlled Atmosphere and Fumigation in Grain Storage, June 1992, Winnipeg, Canada, 121-128.

Rowe S., 2004 - The effect of insect fumigation by anoxia on textiles dyed with prussian blue. Studies in Conservation, 49: 259-270.

Rust M., Vinod D., DruziK J., Presseur F., 1996 - The feasability of using modified atmosphere to control insect pests in museum. Restaurator, 17: 43-60.

Selwitz C., Maekawa S., 1998 - Inert gases in the control of museum insect pests. The Getty Conservation Institute.

Story K., 1985 - Pest Management in Museums. Conservation Analytical Laboratory, Smithson ian Institution, Washington DC.

Strang T., 1998 - Another brick in the wall. Proceedings of the $3^{\text {rd }}$ Nordic Symposium on Insect Pest Control in Museums, 24-25 September 1998, Stockholm, Sweden, 10-29.

VALENTin N., 1993 - Comparative analysis of insect control by nitrogen, argon, and carbon dioxide in museum, archive and herbarium collection. International Biodeterioration et Biodegradation, 32: 263-278. 
Valentin N., Bergh J.E., Ortega R., Åkerlund M., Hallström A., Jonsson K., 2002 - Evaluation of a portable equipment for large scale de-infestation in museum collections using a low oxygen environment. 13th Triennial Meeting. Preprints of ICOM Committee for Conservation, 1: 96-101.

Valentin N., Preusser F., 1990 - Insect control by inert gases in museums archives and archives. Restaurator, 11: 22-33.

Wegener G., 1993 - Hypoxia and post hypoxic recovery in insects: physiological and metabolic aspects. In: Hochachka P.W., Lutz P.L., Rosenthal M., Sick T., van den Tillarth G., Surviving Hypoxia - Mechanisms of control and adaptation, CRC Press, Bocaraton, 4-32.

www.nyalgro.org/enemies\%20of\%20paper05.ppt

http://www.artframe.us/Article-EnemiesofPaper.pdf

Alessia Berzolla, Istituto di Entomologia e Patologia vegetale, Facoltà di Agraria, Università Cattolica del Sacro Cuore, via Emilia Parmense 84, I-29122 Piacenza, Italy.

Email: alessia.berzolla@unicatt.it

Maria Cristina Reguzzi, Istituto di Entomologia e Patologia vegetale, Facoltà di Agraria, Università Cattolica del Sacro Cuore, via Emilia Parmense 84, I-29122 Piacenza, Italy. Email: cristina.reguzzi@unicatt.it

Elisabetta Chiappini, Istituto di Entomologia e Patologia vegetale, Facoltà di Agraria, Università Cattolica del Sacro Cuore, via Emilia Parmense 84, I-29122 Piacenza, Italy.

E-mail: elisabetta.chiappini@unicatt.it 